\title{
Community Participation as Power Distribution: Insight into Law and Practice in Sheka Forests Conservation
}

Samuel Yohanis Degoma * and Tegbaru Terefe Feyissa*

\begin{abstract}
Community participation is a pillar principle in democratic decision-making processes. It is redistribution of power among public institutions, officials and people. With regard to forest conservation, Ethiopian laws and practices in Sheka Zone were examined by using Sherry Arnstein's model of citizen participation. We argue that community participation recognized in the FDRE Constitution falls under the fifth rung of the ladder of citizen participation: placation. In pursuits of forest conservation, the right of the citizens to have their views and opinion be taken into account is not guaranteed. The practice in Sheka Zone ignores the role of community participation, and it does not go beyond the rung of informing. This rung is a stunted one-way communication, and the community members in the Sheka Zone were simply informed about what is planned. Qualitative methodology is employed including legal analysis and literature review with some data collected through interviews, FGD and observation.
\end{abstract}

\section{Key terms:}

Indigenous Knowledge $\cdot$ Community Participation $\cdot$ Forest legislation $\cdot$ Sheka Forest

DOI http://dx.doi.org/10.4314/mlr.v15i2.2

This article is licensed under a Creative Commons Attribution-

NonCommercial-NoDerivs (CC BY-NC-ND)

Received: 29 July 2021

Accepted: 7 November 2021

\section{Suggested citation:}

Samuel Yohanis Degoma and Tegbaru Terefe Feyissa (2021), 'Community Participation as Power Distribution: Insight into Law and Practice in Sheka Forests Conservation', 15(2) Mizan Law Re view: 351-378

\footnotetext{
- Samuel Yohanis Degoma (LLB, LLM), Lecturer of Law at Mizan-Tepi University, School of Law, former judge at Gedeo Zone High Court

Email: yahwenis2013@gmail.com

ORCID: https://orcid.org/0000-0002-2177-3315

* Tegbaru Terefe Feyissa (LLB, LLM), Lecturer of Law at Mizan-Tepi University, School of Law, former dean at Mizan-Tepi University, School of Law

Email: <yemamalig@gmail.com>

ORCID: https://orcid.org/0000-0003-4333-4505
} 


\section{Contents}

Abstract

1. Introduction

2. The Concept of Community Participation

2.1 Defining community participation (CP)

2.2 Significance of community participation

2.3 Level of community participation

2.4 The need to address challenges in community participation

3. Legal Framework to Ensure Community Participation in Forest Conservation

3.1 International legal instruments

3. 2 National legislation

3.2.1 The 1995 FDRE Constitution

3.2.2 Forest Development, Conservation and Utilization Proclamation

3.3 Regional forest laws

4. Community Participation in Sheka Forest Conservation

4.1 Forest conservation efforts

4.2 Subsidiary laws

4.3 Demarcation, designation and environmental impact assessment

5. Concluding Remarks

\section{Introduction}

The concept of 'Community Participation (CP)' is among the basic principles that are envisaged in good governance and democracy. It is also among the most recognized principles in international, regional and national laws. It is adopted in the legal systems of developed and developing countries even though its implementation varies from state to state. $\mathrm{CP}$ stands for "involvement of communities and individuals in decision-making processes that affect their lives". "The task of forest conservation needs meaningful CP because it has a potential to motivate communities and stakeholders. If it is properly implemented, CP can serve as an engine for the

\section{Frequently used acronyms}

$\mathrm{CP} \quad$ Community Participation

FEPOs Forest and Environment Protection Offices

EIA Environmental Impact Assessment

SNNPRS Southern Nations Nationalities and Peoples Regional State

${ }^{1}$ Danny Burns et al (2004), Making Community Participation Meaningful: A handbook for development and assessment, Policy Press, University of the West of England, 2. 
government to realize objectives of environment laws and effective forest management.

The concept of $\mathrm{CP}$ has obtained wider acceptance because of the movements on human rights and activists of environmental protection. The 1977 UN Convention to Combat Desertification and the 1992 Convention on Biological Diversity are typical examples of international legal instruments that clearly call for the application of CP to ensure sustainable utilization of scarce natural resources.

The FDRE Constitution recognizes pluralism that encourages operation of indigenous knowledge which is consistent with the constitutional principles and CP. Other national laws such as environmental laws and forest legislations also require government and public officials to ensure effective $\mathrm{CP}$ in decision-making processes affecting the lives of communities.

This article aims at examining the adequacy of the degree of community participation required to conserve the Sheka forest biosphere. Qualitative methodology is used with due attention to legal analysis and literature review. Qualitative data collection tools such as interviews, focus group discussions and personal observation were employed to collect relevant data. Interviews were conducted with 9 public officials. Two Focus Group Discussions (FGD) were conducted with experts and employees who have experience in relation to forest management tasks. Interviewees and members of FGD were selected through purposive non-probability sampling. The authors have also used data obtained through personal observation.

The next section provides brief discussion of the conceptual framework and highlights the empirical research. Section 3 analyzes the relevant international instruments and domestic laws. The fourth section provides discussion on practices of community participation in Sheka Forest management followed by concluding remarks.

\section{The Concept of Community Participation}

\subsection{Defining community participation (CP)}

The term 'Community Participation [CP]' is "characterized by its diversity of practice and theory. It is an emerging field with many different players using different definitions and with different perspectives." ${ }^{2}$ It can be

\footnotetext{
${ }^{2}$ Involve (2005), People and Participation: How to put citizens at the heart of decisionmaking, p. 16.
} 
defined as the involvement in decision-making process. It can be understood in terms of some level of collaboration and shared ownership or responsibility. ${ }^{3}$ Participation facilitates "the expansion of people's horizons, social contacts and sense of their own power and ability." ${ }^{4} \mathrm{CP}$ is also represented as part and parcel of basic human rights and a pillar principle of democracy that require "involvement of people in a community in projects to solve their own problems."

There are scholars who argue that $\mathrm{CP}$ is an important end unto itself in a democratic society. ${ }^{6}$ It can be considered as a process and an outcome. ${ }^{7}$ Sometimes, members of a certain community may be unwilling to engage themselves in decision making. In this case $\mathrm{CP}$ does not mean that these members should be forced to be involved in decision making process. In democracy it is the people who rule. Therefore, communities should be allowed to "shape the governance process and provide input on decisions to be made by the government so as to ensure meaningful CP." 8

\subsection{Significance of community participation}

Decision-making process in which people meaningfully participate is advantageous for community and government authority. CP, as Sir Bernard Crick described, "provides people with skill and relationships so that they are better able to govern themselves", and it "invokes a sense of ownership and local pride in the local community." The CP helps us build informed and responsible citizens and improves the quality of public life by incorporating the knowledge of the public in decision-making process. ${ }^{10}$ Debble Wilkie

Involve is an organization in the UK (set up in September 2003). It focuses on the practical issues of making public participation work.

${ }^{3}$ Id., 17.

${ }^{4}$ Ibid.

${ }^{5}$ Peter Harvey (2002), Emergency Sanitation: Assessment and Program Design, Loughborough University Leicestershire, 177.

${ }^{6}$ Kathryn S. Quick and John M. Bryson (2016), Public Participation, University of Minnesota Twin Cities Press, 3 - 4,

${ }^{7}$ Burns, supra note 1, p.3

8 Principle of Community Engagement (Clinical and Translational Science Awards Consortium Community Engagement Key Function Committee Task Force on the Principles of Community Engagement $2^{\text {nd }}$ Edition, June 2011) 187.

${ }^{9}$ As cited in Involve (supra 2) p. 20.

${ }^{10}$ Bright Muronda (2017), A Conceptual Public Participation Framework for Ward Committees to Promote Local Government Democracy, MA Dissertation, Potchefstroom Campus of the North-West University, p. 19. 
notes that $\mathrm{CP}$ strengthens the legitimacy of politicians and leads to greater public trust. ${ }^{11}$

The purposes of $\mathrm{CP}$ further include augmenting social justice, informing the public, improving the understanding of public problems, exploring and generating potential solutions, symbolizing ideals of democratic participation and inclusion. It can also be used to produce policies, plans and objects of higher quality. ${ }^{12}$ It enables us to know people's priority, enables better understanding of the problems, provides more ideas about how to address problems, reduces risks of domination by the special interests of elites or groups, facilitates public support for implementation, educates the public and develops a sense of citizenship thereby contributing to the formation of responsive and accountable states. ${ }^{13}$

\subsection{Level of community participation}

Genuine community participation requires acts of "recognizing the intrinsic value of all people, investing in their ability to contribute to governance processes." 14 Bad practices of CP have a potential to create mistrust and waste of people's time and money. For example, it would be very bad practice to "set up a participatory exercise to try to legitimize a decision that has already been taken behind closed doors and which participants are misled into thinking they can affect" the decision. ${ }^{15}$ This can seriously undermine future attempts at public engagement. Bad practices of $\mathrm{CP}$ can be worse than no practice. It should not be used without respect for the participants. ${ }^{16}$

The mere fact that community members are convened in a certain place does not warrant meaningful CP. Representation, power and authority are vital in order to realize quality and legitimacy of the participation. ${ }^{17} \mathrm{CP}$ can take place during need assessment, planning, mobilizing, training, implementing, monitoring and evaluation. Full CP is not the same as

\footnotetext{
${ }^{11}$ As cited in Involve, supra note 2, p.21.

${ }^{12}$ Quick, supra note 6.

${ }^{13}$ International Peace Building Advisory Team (2015), Public Participation and Citizen Engagement, Effective Advising in State building and Peace building Contexts-How, Geneva, Interpeace, pp. 2-3.

${ }^{14}$ Id., p. 7.

${ }^{15}$ Involve, supra note 2, p. 4.

${ }^{16}$ Ibid.

${ }^{17}$ Harvey, supra note 5
} 
consultation because "communities play an active part and have a significant degree of power and influence" in the case of full participation. ${ }^{18}$

Ladder of citizen participation proposed by Sherry Arnestein is one of the most widely referenced and influential models in the field of democratic public participation. ${ }^{19}$ This model "describes how public institutions and officials deny power to citizens and how the level of citizen power can be increased." According to this model, citizen participation is citizen power. It is redistribution of power that enables citizens to be deliberately included in the future. ${ }^{20}$

Arnstein's framework embodies eight 'rungs' of participation. The rungs are manipulation, therapy, informing, consultation, placation, partnership, delegated power and citizen control. The first two rungs (i.e., manipulation and therapy) constitute non-participation. Citizens do not have power in planning and decision making process in the case of manipulation and therapy. These rungs represent illusory form of participation and public officials and administrators create pseudo-participatory programs that attempt to convince citizens.

Informing is the third rung and the most important first step toward legitimate citizen partnership. It refers to an act of informing citizens of their rights, responsibilities and available options. Here, participants are not allowed to give feedback because this step does not provide channel for feedback and there is no power for negotiation. It is one-way flow of information from officials to citizens. It is just telling the people what is planned. Citizens' feedback is not taken into consideration. Listening what has been planned is the only thing required from the people because they are mere observers.

The fourth rung of citizen participation is consultation. It refers to acts of offering some options, listening to feedback, but not allowing new ideas. People are hindered not to come up with new options. Even though people are offered some options, they have no assurance that their concerns and ideas will be taken into account. Officials often use attitude surveys, neighborhood meetings and public hearings. Here, participation is not genuine; rather it is window dressing ritual. Under this rung, effectiveness of participation is measured by the number of people present at meetings and

\footnotetext{
${ }^{18}$ Burns, supra note 1.

${ }^{19}$ Sherry Arnstein (1969), 'A Ladder of Citizen Participation', Journal of the American Planning Association, 35(4), 216-224.

${ }^{20}$ Ibid.
} 
who take brochures. The role played by the participants at the time of meeting does not determine the effectiveness of participation. ${ }^{21}$

The next rung is placation. It occurs when people are granted a limited degree of influence in decision making process. Here involvement of people is required for the sake of demonstrating that they are involved. Participation as placation is tokenistic.

The sixth rung is called partnership, and this "occurs when public institutions allow citizens to negotiate better deals, to share funding." At this stage/rung, power is "in fact redistributed through negotiation between citizens and public institutions". ${ }^{22}$ People have power to influence planning and decision making. It represents acts of encouraging additional options and ideas, and provides opportunities for joint decision making. At this level of 'acting together' not only do different interests of the community decide together; they also form a partnership to carry it out. ${ }^{23}$

The remaining two rungs are delegated power and citizen control. Delegated power is a step that requires public institutions, officials, or administrators to give up some degree of control, management, decisionmaking authority or funding to citizens. The typical example is the situation where a citizens' board or cooperation is tasked with managing community program rather than merely participating in a program managed by public institutions. At this level, citizens hold the significant cards to assure accountability of the bargaining process rather than respond to pressure from the other end. ${ }^{24}$

Citizen control is the final rung of the ladder of citizens' participation. It takes place when citizens are allowed to govern a program or an institution, and in effect, they are "in full charge of policy and managerial aspects", and are empowered "to negotiate the conditions under which 'outsiders' may change them." In citizen-control situations, "for example, public funding would flow directly to a community organization, and that organization would have full control over how that funding is allocated". ${ }^{25}$

${ }^{21}$ Ibid.

${ }^{22}$ Ibid.

${ }^{23}$ David Wilcox (1994), Community Participation and Empowerment: putting theory in to Practice, PLA Notes CD-ROM 1988-2001.

Available at: https://pubs.iied.org/g01549 (Last accessed:2 December 2021)

${ }^{24}$ Ibid.

${ }^{25}$ Ibid. 


\subsection{The need to address challenges in community participation}

Efforts to gain meaningful CP need inclusive approach and trust between government (initiator) and the members of a certain community. Concerned individuals, groups, and organizations must feel they can join a community engagement effort and influence it. "If trust is not present, relationships are guarded and commitments are tentative." ${ }^{26} \mathrm{CP}$ has to be inclusive of the entire community of interest. This (inclusiveness) can create some organizing challenges, such as managing the decision-making process.

However, successfully overcoming these challenges will provide a greater return on the investment made by engagement leaders through the greater involvement of partners and the assets they bring to the process. Clear plan of action is decisive for the proper implementation of CP. Purpose, outcome desired and knowledge of the community determine the legible stakeholders, the strategy and approach used to gain their involvement, and the resource needed. In articulating the purposes or goals of a community engagement effort, we have to know what is of interest and the kind of community involvement that is expected. ${ }^{27}$

The problem of many $\mathrm{CP}$ efforts is that the efforts fail to consider in advance the aforementioned determining factors even though working with the community requires "a continual effort to balance costs and benefits and sustain cooperation and accountability among participating groups" ${ }^{28}$ Although CP plays a crucial role in ensuring sustainable utilization of natural resources and in augmenting attainment of social justice, it is surrounded by many challenges. For example, governments and officials are "reluctant to allow people to participate because of fear of control. They believe that there is only so much power to go around, and giving some to others means losing their own." 29

Ethiopia is not immune from the problems surrounding the CP. There are flaws with regard to the CP even though the 1995 FDRE Constitution and forest legislations require application of the $\mathrm{CP}$ in decisions that have impact on the lives of individuals and community. Studies have identified the existence of various problems in applying or using CP in decision making process.

\footnotetext{
${ }^{26}$ Ibid.

${ }^{27}$ Id., 186.

${ }^{28}$ Id., 187.

${ }^{29}$ Id., 2.
} 
A study conducted by Takele Tuke has identified a gap in community involvement in planning phase. This problem was among the challenges that affected the local community's role in the efforts and endeavors to achieve sustainable development in Aleta Wondo Town administration..$^{30}$ Another study revealed failure of citizens to understand the meaning and importance of their participation in a development project in Oromia Regional State. This failure contributed towards corrupt practices by casting shadow on the involvement of the local community in decision making process. ${ }^{31}$

In another study, unsatisfactory level of CP in budget allocation, decision making and implementation was identified as the main factor that hindered improvements in environmental rehabilitation and agricultural extension development progress in Boloso Sore Woreda. ${ }^{32}$ Moreover, Mesfin and Birhanu have identified gaps in community participation which resulted from institutional, socio-cultural and financial related matters in LegetafoLegedadi Town. ${ }^{33}$ Bad practice in CP has also been manifested in Shebele Berenta district. Willingness for the $\mathrm{CP}$ was very low. Hence, punishment and peer pressure were employed to attain community participation. The $\mathrm{CP}$ in the area was found to be passive and encountered low commitment from the side of government. ${ }^{34}$

Similar problems were identified in a study conducted by Habtamu Degefe and Hendrike Clouting. Poor status of involvement, participation, consultation and lack of adequate information were serious limitations of $\mathrm{CP}$

30 Takele Tuke (2017), 'Role of Local Government for Community Development: A Study in Aleta Wondo Town Administration, Sidama Zone, SNNPR, Ethiopia', Journal of Humanities And Social Science 22(9), p. 6.

${ }^{31}$ Sileshi Leta (2017), 'Assessment of Community Participation on Local Development Projects: The Case of Oromia Regional State,' International Journal of Research in Social Sciences, 7(10), p. 65.

32 Merihun Fikru Meja and Endrias Geta (2017), 'Challenges and Prospects of Community Participation in Improving Environmental Rehabilitation and Agricultural Extension: The Case of Boloso Sore Woreda, SNNPR, Ethiopia', Developing Country Studies, Vol. 7, No. 10, p. 25.

${ }^{33}$ Mesfin Asefa \& Birhanu Girma (2020), 'Community Participation in Integrated Solid Waste Management in Legetafo-Legedadi Town, Oromia Ethiopia', Urban and Regional Planning, Vol. 5 No.1, p. 23

${ }^{34}$ Mengist A., Nurie E., Nega M. (2021), 'Community Participation in the Reduction of Land Degradation: The Case Study of Shebel Berenta District, Amhara National Regional State'. RUDN Journal of Public Administration', 8(1): 59-71, p. 69. 
in irrigation water use in Central Rift Valley. ${ }^{35}$ Other studies also revealed diminished level of community participation in Aleta Wondo district ${ }^{36}$ and various field research sites in Southern Ethiopia ${ }^{37}$ because of constraints such as lack of supportive policies.

The above mentioned studies reveal problems related with Community participation. However, the scope of the studies did not include examination of national laws and practices in relation to the degree of community involvement in the efforts towards the distribution of decision-making powers. This article examines laws and practices of community participation by using Sherry Amstein's Ladder of Participation. Amstein's framework regarding levels of community participation is preferred by the authors of this article because it is "the most famous articulation of participation in terms of the degree to which power is devolved to the community". 38

\section{Legal Framework to Ensure Community Participation in Forest Conservation}

\subsection{International legal instruments}

Severe global problems have forced the international community to shift its focus from the instrumental value of the environment to the intrinsic value of biodiversity. ${ }^{39}$ The UN Convention on Biological Diversity (UNCBD) is among the pertinent international legal instruments devised for the protection, conservation and sustainable utilization of the environment. It aims at achieving the conservation of biological diversity, sustainable use of its components and the fair and equitable sharing of the benefits arising out of its utilization. ${ }^{40}$ The parties to the Convention have affirmed that

35 Habtamu Degefe and Hendrike Clouting (2014), Case Analysis of Public Participation in Environmental Impact Assessment of Irrigation Water Use in Central Rift Valley, Ethiopia, Baltzer Science Publishers, p. 59.

36 Aschalew Hailu and Tefere Makonnen (2016), 'Determinants and Levels of Community Participation in Agricultural Development Programs in Aleta Wondo District of Southern Ethiopia', Journal of Sustainable Development in Africa, Vol.18 No. 4, Clarion University of Pennsylvania, p. 9.

37 Tafesse Matewos Karo (2018), “An Assessment of Youths' Perception and Participation on Environmental Management Undertakings: Empirical Evidence from Youth Development and Change Package Implementation in Southern Ethiopia", Journal of Geography and Regional Planning, Vol. 11(11):183-190, p. 188.

${ }^{38}$ Involve, supra note 2, p. 18

39 The United Nations' Convention on Biological Diversity, (5 June 1992) Preamble

${ }^{40}$ Id., Art. 1. 
conservation of biological diversity is a common concern of humankind. ${ }^{41}$ Under this broad concern, they have expressed commitment towards conserving biological diversity and for its sustainable use. ${ }^{42}$

The Convention requires contracting parties to respect, preserve and maintain knowledge, innovation and practices of indigenous and local communities. It also obliges them to promote the wider application of indigenous practices; and it encourages the equitable sharing of the benefits arising from the utilization of such knowledge, innovation and practices. ${ }^{43}$

The Convention recognizes meaningful $\mathrm{CP}$ as a tool to ensure the respect, preservation and protection of indigenous knowledge and practices which are compatible with the environment. ${ }^{44}$ Moreover, it requires facilitating the exchange of information (from all publicly available sources) relevant to the conservation and sustainable use of biological diversity. ${ }^{45}$ Such exchange of information shall include exchange of result of indigenous and traditional knowledge. Methods of cooperation for the development and use of indigenous and traditional knowledge shall be encouraged and developed so as to rip as much benefits as possible from the treasure of traditional knowledge, practices and experiences. ${ }^{46}$

Another international legal instrument is the United Nations' Convention to Combat Desertification. Combating desertification and drought or mitigating their adverse effects call for joint action of the international community because the causes of desertification and drought involve complex interactions among physical, biological, political, social, cultural and economic factors that cannot be resolved by unilateral actions. ${ }^{47}$

Needless to say, combating desertification and/or drought necessitates due attention to meaningful CP. For instance, the role of local communities is given emphasis to achieve the objective of the Convention which has set $\mathrm{CP}$ as a guiding principle. Consequently, contracting parties are obliged to ensure that decisions, on the design and implementation of programs to

\footnotetext{
${ }^{41}$ Id., preamble paragraph 3,

${ }^{42}$ Id., preamble paragraph 5.

${ }^{43}$ Id., Art. 8(j), Art. 10(c).

${ }^{44}$ Id., Art. 14(a).

${ }^{45}$ Id., Art. 17(1).

${ }^{46}$ Id., Art. 18(4), Art 17(2).

${ }^{47}$ United Nations Convention to Combat Desertification (Convention to Combat Desertification) (1977), preamble para 4 and art 2.
} 
combat desertification and mitigate the effect of drought involve the participation of local communities.

Affected country parties (including Ethiopia) have pledged to establish strategies and priorities to combat desertification and mitigate the effects of drought ${ }^{48}$ and to address the underlying causes of desertification and pay attention to the socio-economic factors that contribute to desertification processes. To this end, they are required to promote awareness and facilitate the participation of local communities. Effective participation of the local population, particularly resource users, in policy planning, decision making, and implementation and review of national action programs are also identified as crucial tools to achieve objectives of the Convention. ${ }^{49}$

The Convention accords outstanding emphasis to the protection, promotion and use of indigenous knowledge. For instance, it envisages exchange of information on local and traditional knowledge and adequate protection to it; and it further requires the integration, enhancement and validation of this knowledge, how-know and practices. ${ }^{50}$ To this end, the parties to the Convention have undertaken to make inventories of such information, knowledge and practices and their potential uses with the participation of the local people. They have also undertaken to facilitate the adoption of such knowledge to wide use and integrate them with modern technology. ${ }^{51}$ These are possible only through meaningful community participation.

Likewise, the International Treaty on Plant Genetic Resource for Food and Agriculture (ITPGRFA) intends to ensure the conservation and sustainable use of plant genetic resources for food and agriculture. In this treaty, contracting parties have recognized the substantial contribution of local and indigenous people in all the regions of the world. ${ }^{52}$

The treaty adopts various mechanisms to realize the conservation and sustainable utilization of plant genetic resources for food and agriculture. Developing and maintaining appropriate policy and legal measures that promote the sustainable use of plant genetic resource for food and agriculture is one of these mechanisms. By appropriate policy, we are referring to policies that include meaningful participation as guiding

\footnotetext{
${ }^{48}$ Id., Art. 5(b), Art 3(a).

${ }^{49}$ Id., Art. 5 (c) and (d) Art 10(2)(e) (f)and Art 19(a) Art 17(f).

${ }^{50}$ Id., Art. 16(g), Art 17(C) and Art 18(b).

${ }^{51}$ Id., Art. 18 (a), (c) and (d).

${ }^{52}$ International Treaty on Plant Genetic Resources for Food and Agriculture (Plant Genetic Resource Treaty) preamble para. 1, id., Art. 9.1
} 
principle. One of the treaty obligations is the promotion and integration of approaches to the exploration, conservation and sustainable utilization of plant genetic resources for food and agriculture and to assess any threat to them. Assessment of threat to plant genetic resource for food and agriculture has to be assisted by utmost efforts of member states to minimize or eliminate the threats. ${ }^{53}$

The Aarhus Convention is the most relevant international legal instrument that provides details on the issues of public participation in decision-making concerning environmental matters. It is aimed at furthering the accountability and transparency in decision-making, and strengthening public support for decisions on the environment. ${ }^{54}$ It obliges state parties to promote environmental education and environmental awareness in order to empower the public to participate in decision-making. ${ }^{55}$ The Aarhus Convention requires state parties to realize the right of the public concerned to be informed (of the proposed activity) early in an environmental decisionmaking procedure, and in an adequate, timely and effective manner. ${ }^{56}$ It gives due attention to ensuring meaningful participation of the public throughout the decision making process.

The decision-making procedure shall include reasonable time-frames to allow sufficient time for informing the public and for the public to prepare and participate effectively during environmental decision-making. The public should have adequate time to submit any comments, information, analyses or opinions that it considers relevant to the proposed activities. State parties to the Aarhus Convention commit themselves to make appropriate practical and other provisions for the public so that it can participate during the preparation of plans, programs and policies relating to the environment. They also undertake to strive to promote effective public participation during the preparation of executive regulations and other generally applicable legally binding rules that may have a significant effect on the environment. ${ }^{57}$ The Convention requires state parties to ensure that due attention is given to the result of public participation. ${ }^{58}$

${ }^{53}$ Id., Art. 5.1, Art 5.1.a , Art 5.2 \& Art 6.1

${ }^{54}$ Convention on Access to Information, Public Participation in Decision-Making and Access to Justice in Environmental Matters, Done at Aarhus, Denmark, on 25 June 1998, preamble, paragraph 10,

${ }^{55}$ Id., Art. 3(3), paragraph 12.

${ }^{56}$ Id., Art. 6(2)(a).

${ }^{57}$ Id., Arts. 6(3), 6(7) and 7(1).

${ }^{58}$ Art. 6(8) and Art 8. 
In a nutshell, international legal instruments have accorded due consideration to $\mathrm{CP}$ for achieving environmental and plant /forest conservation objectives and sustainable development. Hence, parties to these instruments have international obligation to realize the highest possible level of $\mathrm{CP}$ in the development, conservation and utilization of natural resources including forests. As Ethiopia is among the parties to the conventions, the obligations therein are expected to be respected.

\subsection{National legislation}

\subsubsection{The 1995 FDRE Constitution}

The FDRE Constitution, as the supreme law of the land ${ }^{59}$ entrusts the power to enact laws concerning development, utilization and conservation of natural resources to the federal lawmaker ${ }^{60}$ whereas regional lawmakers are empowered to administer natural resources in accordance with laws enacted by the federal government. ${ }^{61}$ The right to improved living standards, sustainable development and the right to participate in national development are recognized by the Constitution. ${ }^{62}$ And according to Article 43(2), citizens "have the right to participate in national development, and in particular to be consulted with respect to policies and projects affecting their community". Moreover, the government has constitutional duty to ascertain that international agreements are complied with and to ensure sustainable development. ${ }^{63}$

On the other hand, the Constitution recognizes formal legal pluralism that enables the application of customary practices and the implementation of indigenous knowledge provided that they are compatible with provisions of the Constitution. ${ }^{64}$ It also embodies a provision that encourages people of Ethiopia to express, to develop and to promote their culture and to preserve history.

The Constitution imposes duty on government to hold, on behalf of people, natural resources including forest, and to deploy them for their common benefit and development. ${ }^{65}$ The initiatives of the people in their

${ }^{59}$ Constitution of the Federal Democratic Republic of Ethiopia, Proclamation

No.1/1995, $1^{\text {st }}$ Year No. 1(21 August 1995) Addis Ababa, Art. 44(1).

${ }^{60}$ Id., Art. 51(5).

${ }^{61}$ Id., Art. 52(2)(d).

${ }^{62}$ Id., Art. 43(1).

${ }^{63}$ Id., Art. 43(3).

${ }^{64}$ Id., Art. 9(1) and Art 34(4).

${ }^{65}$ Id., Art. 89(5). 
development endeavor should also be supported by the government to allow the local community in order to achieve developmental goals. ${ }^{66}$

To this end, the government is required to promote $\mathrm{CP}$ in the formulation of national development policies and programs at all times. Chapter 10 of the Constitution embodies national policy principles and objectives. It requires the Ethiopian government to promote the people's self-rule at all levels ${ }^{67}$ by supporting the growth and enrichment of cultures and traditions that are compatible with fundamental rights, human dignity, democratic norms and ideals and the provisions of the Constitution. ${ }^{68}$ With regard to environmental objectives, the Constitution envisages healthy and clean environment. It provides:

[1] The government shall endeavor to ensure that all Ethiopians live in a clean and healthy environment. [2] The design and implementation of programs and projects of development shall not damage or destroy the environment. [3] People have the right to full consultation and to the expression of views [Emphasis added] in the planning and implementation of environmental policies and projects that affect them directly. [4] Government and citizens shall have the duty to protect the environment. ${ }^{69}$

The words "full consultation" and "expression of views" indicate the required degree of public participation. Under Sherry Arnstein's model, consultation offers some options, listening to feedback. But it does not allow people to come up with new ideas. There are no guarantees that public inputs will influence decision-making because authorities can involve the public as a mere gesture without any commitment to include the views elicited from the people thereby hindering new options to be suggested by the public.

Another issue relates to whether the FDRE Constitution (that guarantees the freedom of expression of views) obliges public institutions and officials to take into account and give due weight to views of people. According to Article 92(3) of the Constitution, quoted above, people have "the right to full consultation" and "to the expression of views ...". Apparently, freedom of expression does not include a corresponding obligation that obliges public institutions to take the views into account. Therefore, the scope of

\footnotetext{
${ }^{66}$ Id., Art. 89(6).

${ }^{67}$ Id., Art. 88(1).

${ }^{68}$ Id., Art. 91(1).

${ }^{69}$ Id., Art. 92.
} 
community participation embodied in the FDRE Constitution seems to be within the rung of "placation." That means the required degree of community participation is not genuine. It is "tokenism" as the involvement of people is required for the sake of demonstrating that they are involved.

\subsubsection{Forest Development, Conservation and Utilization Proclamation}

Efforts have been made to come up with well-organized forest legislation. The enactment of a new Forest Development, Conservation and Utilization Proclamation (hereinafter the Federal Forest Proclamation) is a typical example of such efforts. ${ }^{70}$ It recognizes the important role played by the forest sector "in addressing the adverse effect of climate change" ${ }^{\text {"1 }}$ and gives due attention to sustainable forest development and conservation in the course of utilization. Unlike its predecessors, it has introduced the concept of

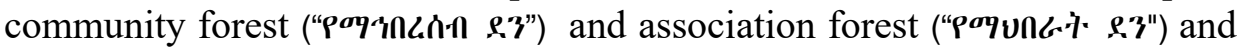
it envisages the implementation of the policy and strategy of sustainable forest development, conservation and utilization to ensure effective $\mathrm{CP}^{72}$

The federal and regional executive bodies are required to formulate forest development, conservation and utilization plan to allow and encourage the participation of local communities in the conservation, development and utilization of the forest. ${ }^{73}$ Once forest management plan is developed by the relevant executive bodies, the conservation, development and utilization of the forest should be in accordance with the requirements in the plan. ${ }^{74}$ Identification and demarcation process of state forests are also required to involve CP. ${ }^{75}$

The new federal forest proclamation uses terms, such as public participation, participation of local communities, participation of community and community participation. This proclamation is a special law with regard to forest development, conservation and utilization. As a special law, it could have identified some details on the elements of community participation in forest conservation.

Unfortunately, there is no indication in the proclamation with regard to the degree of community participation that is required. The Constitution specifies the right of people in planning and decision making process in a

\footnotetext{
${ }^{70}$ Federal Forest Development, Conservation and Utilization Proclamation No. 1065/2018, 24 ${ }^{\text {th }}$ Year No. 21(23 Jan 2018) Addis Ababa.

${ }^{71}$ Id., preamble. para 1.

${ }^{72}$ Id., preamble, para 4.

${ }^{73}$ Id., Art. 12(3), Art. 17(3), Art. 17(8), Art. 19(5).

${ }^{74}$ Id., Arts. 7(1(f)), 12(7), 15(1), 15(3), 19(8), 20(2)\&(3)

${ }^{75}$ Id., Art. 19(3).
} 
manner that is better than the specific forest proclamation. In general the required level of community participation in forest conservation is not specifically determined in the forest proclamation. This opens doors for public institutions and administrators to disregard public concerns.

\subsection{Regional forest laws}

Ethiopia's federal structure empowers the regional Councils to enact laws on regional matters. Accordingly, the Southern Nations Nationalities and Peoples Regional State (SNNPRS) has enacted regional forest proclamation (SNNPRS Forest Proclamation). This Proclamation recognizes the need to utilize the forest resources of the region in sustainable manner by ensuring the participation of the communities. ${ }^{76}$ It indicates the regional state's obligation to ensure $\mathrm{CP}$ when it designates the forests and forestlands of the region as protected forests and productive forest. ${ }^{77}$ Local community shall be encouraged to be active participant and share their experience and knowledge therewith while the management plan is prepared in order to realize the development, conservation and sustainable utilization of forests in the region. ${ }^{78}$

The Proclamation endeavors to ensure the application of knowledge of the people in traditional forest development, conservation and utilization. Hence, it obliges the concerned regional bureau to take traditional knowledge, skill and technologies into consideration in forest management. The bureau is also under duty to ensure the use of indigenous knowledge, practices and technologies in forest development, conservation and utilization. ${ }^{79}$ The objectives of these obligations are to be achieved by "active" participation.

The problem with this stipulation is that the term 'active participation' is not clearly defined in the Proclamation. In the absence of a clear stipulation on the required degree of citizen participation, it is unlikely to ensure fullfledged (i.e., effective and meaningful) community participation. Based on the SNNPRS Forest Proclamation, the regional government has issued a

\footnotetext{
${ }^{76}$ The Southern Nations, Nationalities and Peoples Regional State Forest Development, Conservation and Utilization Proclamation No 147/2012, $18^{\text {th }}$ Year, No. 6 (28 July 2012), preamble paragraph 2 \& Art. 6(1) and Art. 11(3).

${ }^{77}$ Id., Art. 6(1) and Art. 11(3).

${ }^{78}$ Id., Art. 7(2).

${ }^{79}$ Id., Art. 28(3).
} 
subsequent regulation specifically applicable to Sheka protected forests. ${ }^{80}$ This regulation has been issued to designate, demarcate and register Sheka Zone Protected Forest. ${ }^{81}$ The regulation sets standards and principles relating to the protected forest. One of these principles is active CP. ${ }^{82}$ Women and youths of the local community shall be active participants during the preparation of forest management plan, and participate in the survey, conservation, development and utilization of the forest. ${ }^{83}$

The regulation has provisions relating to the use of indigenous knowledge in order to prevent the forest resource from disease and pests. ${ }^{84}$ To this end, the regulation requires stakeholders (in the management of the protected forest) to accord appropriate recognition and support for cultural activities and practices that have been undertaken towards the conservation of forest and forest resources. ${ }^{85}$ Moreover, the regulation clearly expresses the need to conserve and preserve pre-existing cultural values and the indigenous knowledge of the local community regarding the forest resource. ${ }^{86}$

\section{Community Participation in Sheka Forest Conservation}

Sheka Forest is one of the biosphere reserves registered by the UNESCO Man and Biosphere Program. It is located in Sheka Zone of the SNNPRS, Ethiopia. The Zone has three districts: Masha, Andracha and Yeki. It endows extraordinary natural and cultural heritage, mosaic of dense natural forest, cultural forest, managed forests for coffee and beekeeping, bamboo thicket, wetlands, agricultural land and historical sites. The total area covers 238,750 hectares of forest, agricultural and wetlands, bamboo thickets, rural settlement and towns. It comprises Afromontane forest vegetation which has been considered as the world's most threatened eco-region. ${ }^{87}$ The rich culture is an omnipresent part of the biosphere reserve, shaping the

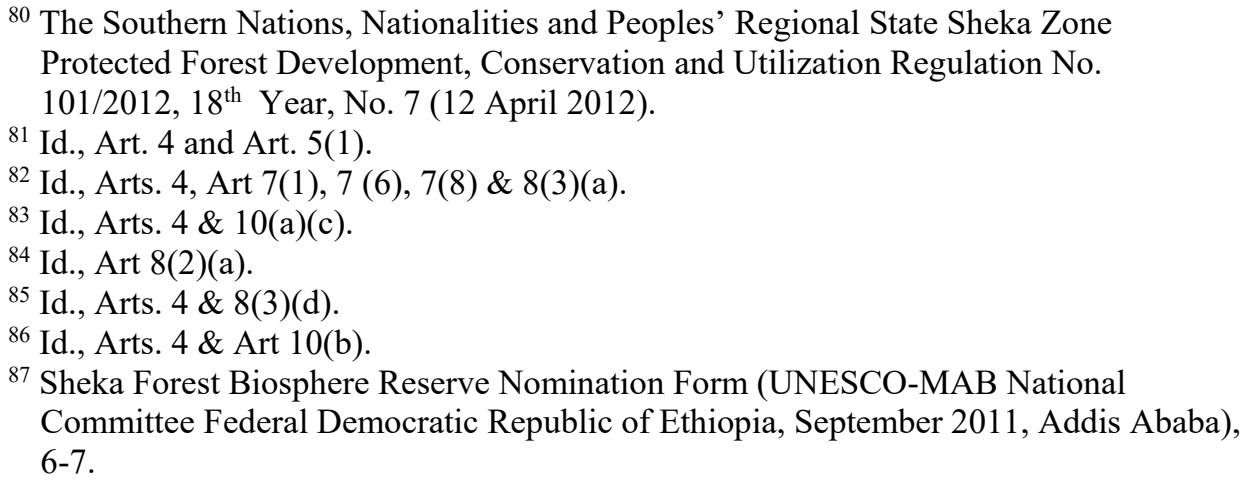


landscape and the sustainable development of the area. ${ }^{88}$ The Sheka forest biosphere embraces over 65 endemic species of plants and birds, and 30 threatened plant species. ${ }^{89}$

This forest biosphere has been maintained by the local community through indigenous knowledge. This is attributable to the distinct culture and human activities which are ecologically sustainable while fulfilling practical needs of the local people. These indigenous forests have economic, ecological and cultural functions to the communities that have ensured the preservation of the forests for centuries. ${ }^{90}$

\subsection{Forest conservation efforts}

Currently, Sheka Forest is decreasing at an alarming rate. This problem is aggravated by multifaceted factors. Households are dependent on natural forest for fuel consumption. The residents of the zone use charcoal and fire wood from the forests. ${ }^{91}$ Officials of local government are reluctant and are not committed to conserve and sustainably use the forest resource in the Zone. As reported by informants, the officials have been permitting many small scale business enterprises engaged in woodwork. ${ }^{92}$ The authors have observed a number of such enterprises in the three districts.

The local government has organized unemployed youths with the objective of job creation who are given license for woodwork enterprises without due caution relating to checking out the sources of the inputs for their woodworks. ${ }^{93}$ The licensing procedures did not consider the subsequent adverse impact of unsustainable usage by the licensed enterprises. There was

${ }^{88}$ See for example, MELCA- Ethiopia: Sheka Forest Biosphere Reserve, Available at: https://melcaethiopia.org/sheka-biosphere-reserve/

Last accessed: 30 November 2021

${ }^{89}$ Sheka Forest Biosphere Reserve Nomination Form, supra note 87.

${ }^{90}$ Id., at 9.

${ }^{91}$ During data collection, the researchers observed some of the community members who were transporting fire wood using horses. Charcoal was also provided to cities by females. Mostly, Masha and Gecha towns along with many villages were totally dependent on fire wood and charcoal as there was no sufficient electric power supply.

92 Interview with Mr. Asmare Chorro, An Expert, Department of Forest and Environmental Protection, Sheka Zone Administration (Masha, Ethiopia 2 August 2010 E.C)

93 The researchers observed various wood work enterprises licensed in the main district towns of Sheka zone in which more than three-fourth was in Tepi town and the rest in Gecha, Gemadirro and Masha. 
no legally recognized private forest in Sheka zone, and it is apparent that the furniture was made of timber from natural forest. ${ }^{94}$ The enterprises (that have no contribution to the development and conservation of the forest) have been using forest products that are conserved by the local community.

Moreover, grave deforestation has been inflicted by large-scale agricultural 'investments' which were grossly introduced in the area. The large scale farms are focusing on coffee ${ }^{95}$ and tea plantations. ${ }^{96}$ The local communities were not involved in the process of identifying appropriate lands for large scale investments. Communities were completely excluded in the process of licensing for woodwork enterprises and identification of lands for large-scale investment. But, the FDRE Constitution requires the government to respect the right of communities to full consultation and to the expression of views in the planning and implementation of environmental policies and projects that directly affect them. ${ }^{97}$

Conservation of forest is one of the pillars and indispensable tasks in the effort to achieve the objectives of forest laws. In order to ensure the implementation of forest laws, the Ministry of Environment and Forest (MEF) was established. Its name was changed to Environment, Forest and Climate Change Commission (EFCCC), and at present it is renamed as Environmental Protection Authority (EPA) as the federal government has committed itself to reduce the number of executive cabinet members. At Zonal and district levels, the Forest and Environment Protection Offices (FEPOs) are established to manage the forests in accordance with the provisions of forest laws.

The FEPOs of Sheka Zone were organized at deputy cabinet level, and the Heads of FEPOs were not members of cabinets. The implication of this structure is that the FEPOs do not have an opportunity to participate in decision making directly; and in the absence of zonal cabinet membership FEPOs find it difficult to have effective voice relating to budget allocation and other decisions. Thus, FEPOs of the Sheka Zone had no chance to influence decision making in budget allocation and other decision making

\footnotetext{
${ }^{94}$ Interview with Mr. Asmare supra note 92.

${ }^{95}$ According to the information from the Sheka zone investment office, there were more than 40 investments which hold roughly more than 10,000 hectares land in coffee and tea plantation.

${ }^{96}$ From the two large scale tea plantations one is in the adjacent Majang zone

${ }^{97}$ FDRE Constitution, supra note 59, Art 92(3).
} 
processes. $^{98}$ Even though the FEPOs are pertinent organs relating to decisions that have impact on environment, the organizational structure of Zonal offices hinders the FEPOs to perform their functions as required by environmental and forest laws.

The FEPOs do not have power to influence the local government to allocate adequate budget to facilitate active $\mathrm{CP}$ at different levels. This adversely affects community participation because the process of ensuring active involvement of communities requires adequate finance and facilities. The structure of the local government was not devised so as to ensure the right of communities to full consultation and to the expression of views in the planning and implementation of environmental policies and projects.

At federal level, the Ministry of Agriculture, Ministry of Water, Minerals and Energy, and the then Ministry of Forest and Environmental Protection had started a forum in order to work together on overlapping issues. Horizontal relation between different sectors which had overlapping interest on environment was created at Zonal and district levels as well. The sectors had devised a forum that comprised eight individuals from different sectors. ${ }^{99}$ It was called 'Climate Resilience Green Economy' forum, commonly abbreviated as (CRGE) ${ }^{100}$ and was led by the FEPO. ${ }^{101}$

According to informants during interviews, the team work was not effective. ${ }^{102}$ Even though there were established institutional structures, the

${ }^{98}$ As the researchers noticed from the official reports and records, human resource both at zonal and Woreda levels was by far below expected; and annual budget of the office was Birr 133,000. The office had only two motor bicycles to coordinate the work within the Zone. Masha Woreda Forest and Environmental Protection Office annual budget was only Birr 25,000 during the budget year 2010 E.C. (July 2017-June 2018).

${ }^{99}$ Interview with Mr. Abebe Atto, Expert, Forest and Environmental Protection Office of Masha District ( Masha, Ethiopia 3 Nehassie 2010 E.C/ 9 August 2018)

100 Forest and Environmental Protection Office, Investment Office, Agriculture and Natural Resources Conservation Office, Police Station, Office of Public Prosecution, Court and Biosphere Reserve Offices are members of CRGE

101 Interview with Mr. Tamiru Digo, Expert, Investment Department, Sheka Zone Administration (Masha, Ethiopia 7 Nehassie 2010 E.C/ 13 August 2018) and Interview with Mr. Tadesse Shobeno, Expert, Agriculture and natural resources conservation Department, Sheka Zone Administration (Masha, Ethiopia, 7 Nehassie 2010 E.C/ 13 August 2018)

${ }^{102}$ Interview with Mr. Biruh Tesfaye, Head, Department of Biosphere Reserve, Sheka Zone Administration (Masha, Ethiopia 9 Nehassie 2010 E.C/ 15 August 2018) 
cooperation among the sectors was poor and inefficient. ${ }^{103}$ Such forum is very important as it can serve as an opportunity to bring the relevant institutions together to address shared concerns. However, the CRGE did not embrace members from the community elders and individuals who have adequate traditional knowledge, practices and experiences. The Forum included different experts and cabinets, but it failed to include representatives from local elders and clan leaders.

This clearly shows that $\mathrm{CP}$ had been ignored in the efforts of government organs to conserve Sheka forest biosphere. Involvement of local communities in the forum would have enabled the use of indigenous knowledge, experiences and practices to ensure sustainable management of the forest. As Nishizaki noted, such exclusion of local community in the task of conservation was a cause for Arssi Oromo community to resist the imposed conservation policies by using different tactics. ${ }^{104}$ The government should take a big lesson from the resistance of the Arssi Oromo community towards imposed policy of the Swayne's Hartebeest Sanctuary conservation. This verifies that there cannot be sustainability of policies, projects and the environment in the absence of high levels of community participation.

\subsection{Subsidiary laws}

The Federal Forest Proclamation empowers regional states to administer any forestland and state forest found in the respective regional states. ${ }^{105}$ It empowers Council of Ministers and Ministries to come up with regulation and directives necessary for its implementation. ${ }^{106}$ In order to realize the implementation of forest laws, there have to be regulations, directives and guidelines that specify details relating to issues of $\mathrm{CP}$ and that indicate the approaches to be used to incorporate indigenous knowledge in forest management tasks.

In practice, however, the FEPOs and other sectors had no subsidiary laws such as guidelines that specify how local communities should be represented in decision making processes impacting their lives and the approaches that are required to be followed in order to incorporate indigenous knowledge, experiences and practices with regard to ensuring forest development, conservation and sustainable use. Provisions in federal and regional forest

\footnotetext{
${ }^{103}$ Ibid.

${ }^{104}$ Nobuko Nishizaki (2004), 'Resisting Imposed Wildlife Conservation: Arssi Oromo and the Swayne's Hartebeest Sanctuary, Ethiopia', African Study Monographs, Vol. 25 No. 2: 61-77, p. 72.

${ }^{105}$ Federal Forest Proclamation, supra note 70, Art. 17.

${ }^{106}$ Id., Article 27.
} 
laws are general and they are not self-executing provisions. These laws also lack provisions that indicate accountability and administrative measures against office holders who -intentionally or by negligence- ignore the right of the local community to participate in the planning and decision making process.

The regulation that governs the administration of Sheka protected forest lacks detail rules that ensure the implementation of local communities' right to participation. Although it requires active participation of the community, the term 'active participation' has not been defined thereby rendering it difficult to clearly identify the required degree of community participation in the conservation of Sheka Forest.

\subsection{Demarcation, designation and environmental impact assessment}

As stipulated under the Federal Forest Proclamation, in order to conserve, develop and utilize preserved forests, "... major forestlands shall be designated as state forests, their boundaries shall be demarcated and they shall be registered as protected and productive forests". ${ }^{107}$ The demarcated state forest "shall be proclaimed by legislation of the concerned state". ${ }^{108}$ Demarcated and designated state forests need also to have "certificate of title deed which is to be supported by maps". ${ }^{109}$ Demarcation, designation and certification were intended, among other things, to serve as credible evidence.

Such demarcation and designation would indeed require effective CP. ${ }^{110}$ Sheka Zone protected forest is designated, demarcated and registered by regulation. ${ }^{111}$ This is a commendable progress. Nevertheless, the designation and demarcation processes were not participatory. The local community was not even informed whether protected forests around them are designated, demarcated and registered. ${ }^{112}$

Environmental Impact Assessment (EIA) is among the tools that can be used to conserve resources by ensuring sustainability of uses. The main

\footnotetext{
${ }^{107}$ Id., Arts. 14(1) \& 13(4).

${ }^{108}$ SNNPRS Forest Proclamation supra note 76, Art. 6(1).

${ }^{109}$ Federal Forest Proclamation supra note 70, Arts.12(10), 13(4) \& 14(3)

${ }^{110}$ Id., Art. 8(2).

111 Ibid.

${ }^{112}$ FGD held in Andracha District (Discussion with Forest and Environmental Protection Office, Investment Office, Agriculture and Natural Resources Conservation Office, Police Station, Office of Prosecution, Court and Biosphere Reserve Offices held on 24 September 2018/ 14 Meskerem 2011 E.C).
} 
objective of the EIA is to ensure sustainability of projects, programmes and activities. The EIA needs CP for sharing information and knowledge to enhance community interest. ${ }^{113}$ In this regard the local community of the study area had a commendable culture:

The clan and ritual leader, the 'Gepi-tato', is at the heart of the land-tenure and forest-management system, as his permission is required before anyone may clear forest or acquire farming land. For example, when a resident or newcomer is looking for farmland, he must appear before the clan leader, who then consults with the clan, assesses land availability and performs rituals to purify the land before it is handed over to the new holder. According to religious beliefs, settlement or clearing for agricultural activities is never allowed on land that is in contact with forest areas, cultural places, wetlands and headwaters. ${ }^{114}$

The quote above shows the indigenous practice that has preserved the Sheka forest through generations. As one of the most respected clan leaders stated: '[w]e have the moral obligation to transfer the forest which we inherited from our forefathers'. ${ }^{115}$ This culture is also meant to contribute much for the preservation of the dense forest in the area.

As the key informants and the FGD participants reported at the time of data collection, the investment license provision procedures were problematic. Huge projects that need prior Environmental Impact Assessment were permitted without ensuring the effective participation of local communities. The power of Zonal Investment office to examine and approve the EIA was limited to projects that require less than 100 hectares of land. For investment projects that need greater than 100 hectares, EIA was to be approved by the regional office which is very far thereby usually causing reluctance to come down to the area to assess the realities on the ground. Officials of regional bureau and Zonal offices were perceived, by respondents, as close friends of investors, and they failed to ensure the

${ }^{113}$ Dejene Girma (2010), 'Environmental Democracy in Ethiopia: Emphasis on Public Participation in Environmental Impact Assessment Process"), Bahir Dar University Journal of Law 1(2), 210.

${ }^{114}$ Interview with Mr. Kedane Dachachew, Administrator, Wollo kebele (Masha District Wollo Kebele, Ethiopia, 17 Nehassie 2010 E.C/ 23 August 2018); See also $<$ https://sacredland.org/sheka-forest-ethiopia/ > Accessed on 20 December, 2018

115 Interview with Mr. Atestata Dakito, Atesso clan leader, (Atesso kebele, Masha, Ethiopia, 20 August 2018). 
implementation of the forest proclamation and regulation because of their affiliation with investors or corruption. ${ }^{116}$

The social values that maintained the Sheka forests have been eroded by misconduct associated with large-scale farms. The local people are increasingly becoming engaged in selling their oxen and buying horses for charcoal transportation to the nearby cities." 117 Unsustainable large scale investments have (in the behaviours of many members of the youth) cultivated counterproductive tendencies of monetary gains through deforestation. Moreover, "efforts to create awareness have encountered great challenge and the confidence of the people have been eroded." 118

Even though effective forest conservation needs application of indigenous knowledge, practices and experiences, clan leaders and elders were not allowed to share such kinds of knowledge and skills. ${ }^{119}$ Because of the failure to respect the right to grassroots participation, local communities were not in the position to participate in EIA procedures and contribute indigenous knowledge, experience and practices which are proved to be sustainable in practice.

The officials and experts of the FEPOs did not ensure participation of the local community at required levels. The communities were not allowed to accord feedback on the proposed project. Officials and experts often announce plans and try to convince the community. They did not have guidelines or directives that provide for schemes which can integrate or use indigenous knowledge, practices and skills in day to day tasks. Hence, there seemed to be one-sided focus on what seemed to be advantageous with respect to 'economic development'. ${ }^{120}$

Sheka Forest conservation practices were insensitive to local communities because the communities, as stated above, were excluded from the task of forest management. This violates the constitutional rights of the local community members to develop and to promote their culture and to preserve its legacy of forest conservation. ${ }^{121}$ Sovereign power does not

\footnotetext{
${ }^{116}$ Interview with Mr. Tadesse Shobeno, supra note 101.

117 Ibid.

${ }^{118}$ Interview with Mr. Girma Haile, Head, Department of Youth and Sport Affairs, Sheka Zone (Masha, Ethiopia 23 Hamle 2010 E.C/ 30 July 2018).

119 Ibid.

${ }^{120}$ See, for example, SNNPRS Forest Proclamation, supra note 76, Art. 20(2).

${ }^{121}$ FDRE Constitution, supra note 59, Art 39(2) and 93(4)(c).
} 
reside in officials and experts. Officials are delegates of the people. ${ }^{122}$ Delegation of citizens' power to political representative does not mean that authority of communities is undermined. ${ }^{123}$ As discussed above, the right of communities in Sheka Zone to actively participate and influence decisionmaking processes affecting them was undermined by government organs that did not pay attention to identify and address the priority of the community. This is susceptible to eventual widespread dissatisfaction.

Ignoring the community in the conservation of the forest amounts to disrespecting them. They should be given a chance to be involved and substantially affect decisions, policies and projects. The government organs should respect these communities who have maintained distinct culture that enhances ecological sustainability. Failing to do so discourages the legacy of community engagement in forest conservation.

\section{Concluding Remarks}

Community participation is one of the pillars of democratic governance. It enables public institutions, officials and local communities to work together to increase trust, outcome and positive impact of decisions and projects. International and national environmental laws and forest legislations oblige Ethiopian government organs at federal and local levels to ensure the development, conservation and sustainable utilization of forest resources through effective $\mathrm{CP}$ and the use of indigenous knowledge.

Ethiopia recognizes legal pluralism ${ }^{124}$ and CP. However, we argue that the degree of community participation recognized by the FDRE Constitution is placation. It does not ensure that the rights of citizens to have their views and opinions are taken into account. The maximum right given for the community is the right to full consultation and to the expression of views. In view of Sherry Arnstein's Ladder of Citizen Participation, the degree of participation recognized by the Constitution is narrower than the scope of participation that are articulated under federal and regional forest laws.

Even though federal and regional forest laws set broader and attractive purposes and objectives with regard to $\mathrm{CP}$, they lack clarity. It is indeed commendable that they require concerned government bodies to ensure $\mathrm{CP}$

\footnotetext{
${ }^{122}$ Id., Art. 8.

${ }^{123}$ Muronda, supra note 10, p. 23.

${ }^{124}$ FDRE Constitution, supra note 59, Art 9(1) impliedly recognizes customary practices that do not contravene the Constitution.
} 
in the development, conservation and utilization of forest resources. They, however, fail to clearly specify the required degree of community participation. It is difficult to identify the exact rung in the ladder of citizens' participation because the laws use general terms, such as 'active participation' that are not defined in the laws.

The actual practice in the Sheka Zone forest preservation is problematic. Even concerned offices in the Zone do not have power to negotiate and influence decisions of cabinets. The officials of Forest and Environmental Protection Offices (FEPOs) are not among the decision makers.

Although legal reforms that have been made so far are commendable, utmost attention should be given to detailed guidelines that facilitate and ensure effective community participation at regional level. Moreover, the FEPOs should be members of cabinet in regional states, and the officials of local government must respect the right of people to full consultation and to expression of ideas as prescribed in the Constitution.

In this regard, what is enshrined in the Constitution should materialize through effective and legitimate citizen partnership. Moreover, enhanced levels of CP are required through amendments in the FDRE Constitution, the federal forest proclamation and regional forest laws. Failure to do so will have grave adverse impact because precious knowledge of local communities will continue to be ignored. This can eventually lead to the loss of the dense Sheka Forest and the biosphere in the zone. 


\section{Cited References}

Arnstein, Sherry (1969). 'A Ladder of Citizen Participation', Journal of the American Planning Association, 35(4).

Aschalew Hailu and Tefere Makonnen (2016). 'Determinants and Levels of Community Participation in Agricultural Development Programs in Aleta Wondo District of Southern Ethiopia', Journal of Sustainable Development in Africa, Vol. 18 No. 4, Clarion University of Pennsylvania.

Burns, D. et al (2004). Making Community Participation Meaningful : A handbook for development and assessment, the Policy Press, University of the West of England

Degefe, H. and Clouting, H. (2014). Case Analysis of Public Participation in Environmental Impact Assessment of Irrigation Water Use in Central Rift Valley, Ethiopia, Baltzer Science Publishers.

Dejene Girma (2010). 'Environmental Democracy in Ethiopia: Emphasis on Public Participation in Environmental Impact Assessment Process', Bahir Dar University Journal of Law, 1(2).

Harvey, Peter (2002). Emergency Sanitation: Assessment and Program Design, Loughborough University Leicestershire.

Mengist A., Nurie E., Nega M (2021). 'Community Participation in the Reduction of Land Degradation: The Case Study of Shebel Berenta District, Amhara National Regional State'. RUDN Journal of Public Administration, 8(1): 59-71

Merihun Fikru Meja and Endrias Geta (2017). 'Challenges and Prospects of Community Participation in Improving Environmental Rehabilitation and Agricultural Extension: The Case of Boloso Sore Woreda, SNNPR, Ethiopia', Developing Country Studies, Vol 7, No.10.

Mesfin Asefa \& Birhanu Girma (2020). 'Community Participation in Integrated Solid Waste Management in Legetafo-Legedadi Town, Oromia Ethiopia', Urban and Regional Planning, Vol. 5 No.1.

Muronda, Bright (2017). A Conceptual Public Participation Framework for Ward Committees to Promote Local Government Democracy, MA Dissertation, the Potchefstroom Campus of the North-West University

Nishizaki, Nobuko (2004). 'Resisting Imposed Wildlife Conservation: Arssi Oromo and the Swayne's Hartebeest Sanctuary, Ethiopia', African Study Monographs, 25 (2)

Quick, K.S. and Bryson, J.M. (2016). Public Participation, University of Minnesota Twin Cities press

Sileshi Leta (2017). 'Assessment of Community Participation on Local Development Projects: The Case of Oromia Regional State', International Journal of Research in Social Sciences, 7(10)

Tafesse Matewos Karo (2018). “An Assessment of Youths’ Perception and Participation on Environmental Management Undertakings: Empirical Evidence from Youth Development and Change Package Implementation in Southern Ethiopia”, Journal of Geography and Regional Planning, Vol. 11(11):183-190.

Takele Tuke (2017). 'Role of Local Government for Community Development: A Study in Aleta Wondo Town Administration, Sidama Zone, SNNPR State, Ethiopia', Journal of Humanities and Social Science, 22(9)

Wilcox, David (1994). Community Participation and Empowerment: putting theory in to Practice, PLA Notes CD-ROM 1988-2001. 